\title{
Fostering Critical Thinking in the Classroom
}

\author{
Husniah Sahamid \\ Faculty of Educational Studies, University Putra Malaysia \\ 43400 Serdang, Selangor, Malaysia \\ E-mail: husniah@upm.edu.my
}

Doi:10.7575/aiac.alls.v.5n.6p.166

Received: 13/08/2014

URL: http://dx.doi.org/10.7575/aiac.alls.v.5n.6p.166

Accepted: 09/10/2014

\begin{abstract}
The ability to cite reasons, to justify claims and give support to arguments is seen as primary characteristics of a critical thinker. This paper discusses how the 'Elements of Reasoning' is employed with Socratic Questioning to develop critical thinking in the language classroom. The principles that guide the questioning are laid out clearly, just as is the response which must be backed by valid reasons, examples, and illustrations, pushing students beyond mere recall and into abstract thinking. It is based on the notion that through questioning, the process that occurs in the student's mind creates thinking and learning.
\end{abstract}

Keywords: Socratic questioning, critical thinking, classroom activities

\section{Introduction}

An education system that is heavily exam oriented has led to produce students who are rote learners and lacking in critical thinking skills (Rahimah $\mathrm{Hj}$. Ahmad, 1998). The system has also encouraged teachers to teach in a way that allows them to cover the syllabus in the shortest time possible, mostly achieved through didactic teaching. Completing the syllabus ahead of time allows teachers to conduct more revisions and drilling sessions in preparation for the exams. In these session, students memorize facts and concepts as teachers take them through numerous past year exams questions and especially the model answers. The irony of it is that students who learn through memorization and rotelearning are generally unable to analyse, interpret, or justify their opinion with reasons (Paul, 1993, 2000).

The ability to think logically and abstractly and to reason theoretically, are characteristics of critical thinking (Paul, 1993; Paul and Elder 2007). According to Piaget (1977), these skills are descriptive of those in the formal operations stage, which typically begins at the age of adolescence. At this stage individuals are capable of imagining different possibilities in a given situation, analyzing problems and applying concepts and determining solutions for varied situations. This stage, beginning approximately at the age of eleven or twelve, is considered the ultimate stage of development. However, students will not experience cognitive activity for developmental change and consequently will not advance to the formal operations if not exposed to appropriate new situations and opportunities.

Mere exposure to appropriate situations and opportunities is not sufficient for developmental change to occur. Smock (1981) states that when students attend lectures or when they observe experiments conducted by the teacher, they do not necessarily experience cognitive activity. For developmental change to occur, students must not only be presented with opportunity but must experience a state of disequilibrium which leads to motivate students' learning into the formal operations stage. The learner must be exposed to situations where he "must be involved in the personal striving for cognitive coherence" and to acknowledge that the task is a "problem" (Ibid, 1981:59). In other words, students will not graduate to the formal operations stage of reasoning if they are not exposed to situations where they are required to 'think'. The problem is not students' disinterest or lack of ability to learn in such a way but that they are not presented with sufficient opportunity to do so (Precel, Eshet-Alkalai, \& Alberton, 2009).

\section{Critical Thinking for the Classroom}

Paul's concept of critical thinking is practical and can be adapted for classroom instruction. He uses 'The Elements of Reasoning' with Socratic Questioning to promote learning and develop critical thinking in the classroom. It is based on the notion that through the questioning, the process that occurs in the student's mind creates learning (Applebee et al, 2001;Overholser, 1992; Paul, 1993, 2000). Students' learning and thinking is fostered through a wide range of probing questions posed to students and guided into providing reasons for their responses. The strategy pushes students beyond merely recall and into abstract thinking.

Paul sees the 'Elements of Reasoning' as the best way to create this disequilibrium. The 'Elements of Reasoning' compels students to think. Students arrive at critical thinking because questioning compels the person to respond with valid reasons in a systematic manner (Paul, 1993, 2000). The principles that guide the questioning are laid out clearly, just as is the response which must be backed by valid reasons, examples, and illustrations. The questioning makes demands on the person questioned to think of other situations; the argument has to be free of mere conjecture and opinion and requires the person to think beyond the present, to think of other situations and even predict outcomes in 
those likely situations. (Ibid, 1993) A student's thinking is further heightened by other students' views and questions and contributions on the topic of discussion which are also sought during the process of questioning.

\subsection{Critical Thinking and 'The Elements of Reasoning' (EOR)}

According to Paul there must be a general logic to reasoning and this is done by disciplining the mind according to a "structure" (Paul, 1993: 114) provided by EOR. Good thinking is derived from good questions, from asking questions that stimulate thought (Paul and Elder 2001). The quality of questions we put forward determines the quality of thought. To become skilled at reasoning students have to take apart their thinking and make explicit what is "beneath the surface" of thought (Paul, 1993:106). The student is guided into disciplining his mind to reason out any problem or task by going through the eight EOR: Purpose, Question, Assumptions, Inference, Implications, Point of View, Concepts and Information. The teacher asks a series of questions under the different elements and guide students to provide illustrations, examples, analogies and evidences to bring it to a 'standard' of reasoning through discussions and planned classroom activities. The teacher disciplines students' thinking by routinely going through items on EOR throughout the teaching of the course to have them become better and better at reasoning.

\subsubsection{The Elements of Reasoning}

Questions are important because questions give direction and help focus our thought.

- Questions of Purpose force us to define our task.

- Questions of the Problem or Issue forces us to focus on what is the problem or issue that we are working at.

- Questions of Information force us to look at the sources of information as well as the quality of the information we have.

- Questions of Inferences or Interpretation force us to examine how we are organizing or giving meaning to information and to consider alternative ways of giving meaning.

- Questions of Assumption force us to examine what we are taking for granted, what are our assumptions and if they are justifiable.

- Questions of Consequence or Implication force us to follow where our thinking is leading us.

- Questions of Point of View force us to examine our point of view and to consider other relevant points of view.

- Questions of Concepts force us to look at models, theories and help us define our ideas

(Adapted from Paul and Elder (2001:114)

At the same time, The Universal Intellectual Standards model (Paul \& Elder, 2007) is also used to ensure quality of reasoning during the questioning session to further probe students' thinking. These are classified into eight categories and used for the following purposes and functions:

Clarity (to understand clearly what a person is saying)

Accuracy (when a statement is clear but not exact)

Precision (when a statement is not stated explicitly or in detail)

Relevance (when a statement is not relevant to the issue)

Depth (when a statement is superficial)

Breadth (when a statement shows only one point of view)

Logic (when a statement does not make sense)

Significance (when the most important problem is not considered in a statement)

Fairness (statement reflects a partiality, preference, or prejudice)

(Paul and Elder (2007, p. 5-9). 
Teachers use their creativity to develop a variety of activities to foster critical thinking in the English language classroom using Paul's 'Elements of Reasoning'. The following are examples of ways the EOR can be used to foster critical thinking skills

In the first activity students are provided with a reading stimulus for a reading and comprehension language exercise. The reading stimulus helps students with learning the language. Teachers, however can use the reading stimulus to also foster critical thinking skills in students. In this activity, students participate in a critical thinking exercise on how to evaluate a problem presented and how to respond to a particular letter. Often, the inability to resolve issues or problems is linked to their inability to weed out unimportant or irrelevant information. Students go through a system of thinking to identify the problem by taking apart the problem. Defining the real issue is actually the first step towards coming to an appropriate solution.

\section{ACTIVITY 1}

Language: Reading and Comprehension

Critical Thinking Exercise: Evaluating a problem

Students are provided with a letter from a national daily and use the EOR to guide their thinking and their understanding of the contents of the letter.

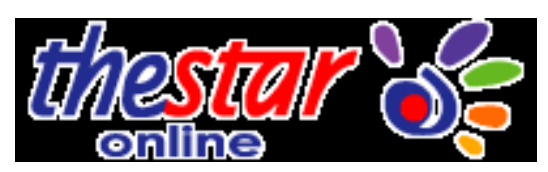

Letter to the Editor

Stop employees from moonlighting

It is imperative that the Government stops its employees from holding a second job, or running a business parallel to their duties in government service. Employees in the private sector should also be forbidden from moonlighting.

It is very difficult for any servant to serve two masters at the same time, and employees who hold two or more jobs at the same time are bound to perform poorly in both of them.

Government servants should lead the way in following the code of ethics and projecting proper behaviour.

The expectations from civil servants are great and taxpayers would want them to perform well and with full commitment and devotion.

MARISA DEMORI,

Perak

Instructions: Read the 'Letter to the Editor' and write down your responses in each of the eight categories of the EOR table.

\begin{tabular}{|l|l|}
\hline Elements Of Reasoning (EOR) & Responses to EOR Questions \\
\hline What is the purpose of the letter? & \\
\hline What is the real issue / problem? & \\
\hline $\begin{array}{l}\text { What are some assumptions we can make about the } \\
\text { letter/the writer? }\end{array}$ & \\
\hline Are there other points of views that we need to consider? & \\
\hline
\end{tabular}


What inferences can we make about the writer?

What inferences can we make about the reasons for write writing the letter?

What information is the writer providing us?

Is this information true/relevant/sufficient?

What other information do we have that can add to our understanding of the issue?

What rules/concepts do we need know to understand what is going on?

What is meant by the 'moonlighting'?

Is there an explicit law against 'moonlighting' - for civil servants, those in the private sector?

What could be the consequence of this letter?

What does the writer hope to get out of this letter?

Are there any other implications?

Would you say this is an effective letter?

Completing the exercise in ACTIVITY 1 means that students have managed to successfully define the real issue or problem presented in the letter. They are now more likely to be able to respond to the problem because they have understood the problem.

In ACTIVITY 2 students summarise their thinking and are guided into replying to the writer based on their responses in the EOR. They do this by applying the information tabulated in the EOR table. Student employ the tools of thinking using the EOR and are guided into offering an appropriate solution.

\section{ACTIVITY 2}

Language: Oral and Writing Exercise

Critical Thinking: Offering appropriate solutions

(i) Discuss with a partner how you would respond to the Marisa Demori. Give your opinion using your responses on the right column of the EOR table.

The following is a sample of what students will produce in their writing exercise:

Dear Ms. Demori,

I am writing this in response to your letter in the Star dated Thursday June 24, 2010. (purpose).

I understand the issue that you are concerned with is that of government employees holding second jobs (main issue/problem). I assume that you are writing this letter because you were the probably recipient of bad service from an employee whom you infer must be holding a second job; perhaps he/she was unable to serve you appropriately due to him/her holding a second job (inference, assumption).

For your information, government employees who earn less than RM 2,500 a month are reported to have difficulty making ends meet especially if they live in the city and has more than one dependent. (information, point of view). The government policy on this is that .... (rules/information). The labour law is also very clear on the issue of employees having second jobs..... (rules/concepts, information, point of view).

In conclusion, ....... (consequence) 
This exercise also teaches students the importance of getting their facts and information straight. In this activity, students need to decide what kinds of information are needed (labour law, government policies) and where can such information be obtained. The teacher can conduct a brief discussion on this before students undertake to write a response to Ms Marisa.

In the next activity students learn to separate fact from opinion and evaluate whether a piece of material is written based on information and reason, or written from a biased an emotional point of view. Students are given an article, they take the article apart and analyse it by writing down the information under the eight categories of the EOR. The teacher then questions students for a critical discussion on the article.

\section{ACTIVITY 3}

Language: Reading and Comprehension, Oral

Critical Thinking: Evaluating Fact from Opinion

Sample of questions for discussion:

- Are you able to fill in information into all of the eight categories of the EOR table? (The response will be 'NO')

- Which are some of the categories in which you are unable to fill in or respond to?

- It is common to find in biased reports or articles, information missing especially under the categories of 'point of view' and 'information'

- Do you think this is done on purpose by the writer?

- What could be the consequence of purposefully leaving out certain details in these categories?

The teacher further conducts a critical discussion on:

(i) how opinion can be made to look like fact \& information,

(ii) speaking/writing from emotions is not fact/opinion,

(iii) ways to check for validity of information.

\section{ACTIVITY 4}

Language: Literary Analysis \& Discussion

Critical Thinking: Giving reasoned opinion

The following an activity to help students do a critical analysis of a poem. Often, teachers want to teach students to analyse but do not know where to start. Here, a structured and systematic way of asking questions helps students to analyse a literary piece. An important aspect of the strategy of Socratic Questioning is that the questions are prepared by the teacher prior to class. Spontaneous questions that emerge during the discussion are fine but the main questions are prepared beforehand so as to control the direction of the discussion. Questions from the EOR and the follow-up questions are posed to students for elaboration, clarification and justification of opinion/statements.

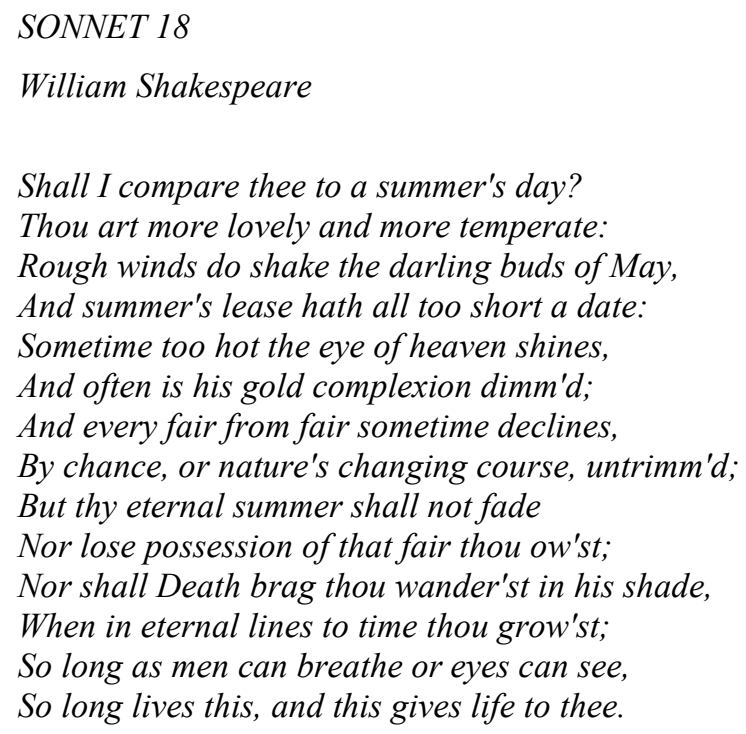


1. What do you think is the purpose of the poem? Why do you think the poet wrote the poem? (purpose)

- Why do you say so/ what makes you think that?

- What is the evidence of this? What do you base your opinions on?

2. What is the poem mainly about? What is the poet's main point/topic? (issue/problem)

- What is the poet trying to do by comparing his love and a summer's day?

- What are some of the descriptions of summer as depicted by the poet?

- What can inference can we make from the comparison? (inference)

3. This poem is called a Sonnet. What is a sonnet? (information, concept)

- Can this be called a true sonnet?

- Why/Why not?

- Is the form (sonnet) effective in conveying the poet's feeling?

4. What assumptions can you make about the persona? (assumptions)

What assumptions can you make about the person the poem is dedicated to?

- On what are these assumptions based?

- Is this assumption fair?

5. The poem is written from whose perspective? (point of view)

- What do you think was the response of the recipient of the sonnet?

- If a sonnet was written for you what would you like to be compared to?

- If it was you, how would you like someone to show their appreciation of you?

6. What do you think is the consequence of writing this poem? (consequence)

- What do you think is the poet hoping to achieve from this poem?

- What do you think happened as a consequence of the sonnet?

The teacher then facilitates a whole class discussion using appropriate questioning techniques to lead students into giving thoughtful and meaningful responses. At the end of the lesson the teacher summarises what has been discussed.

\section{Conclusion}

The possibilities for creating critical thinking activities based on the EOR for the classroom is endless as can be seen by the examples provided. Socratic questioning can be time consuming since teachers will have to allow for pauses and sufficient wait time to get the appropriate responses from students. Holme (1992) agrees that this is the drawback; his research show that 15 to 20 per cent less content material will be covered due to the pauses. Nevertheless, he also states that "students' understanding of fundamental topic is improved and therefore the percentage is arguably acceptable" (Holme, 1992, p 975). Initially, it may appear that precious time is 'lost' in guiding students to discipline their thought to a structured system. Expect for discussions to be stilted and awkward as students adjust to this new mode of learning. Eventually both teacher and student will find it easier as students become more adept at skills which call for analyzing, evaluating, rationalizing and justifying. Needless to say incorporating good questioning techniques, like giving students sufficient wait-time, giving appropriate feedback will assist teachers to conduct Socratic questioning effectively.

The world we now live in highly challenging. The rapid advancement of knowledge has made it incumbent upon the teacher to teach students skills not merely to cope but to succeed in this new and changing world. The employment of critical thinking strategies and activities in the classroom will help students to cope with the challenges they will face later. Paul's system is one effective way to arrive at fostering critical thinking skills. Incorporating the strategy in all disciplines across the curriculum would certainly be a move towards the right direction.

\section{References}

Ahmad, R. (1998). Educational development and reformation in Malaysia: past, present and future. Journal of Educational Administration, 36(5), 462--475.

Applebee, A., Langer, J., Nystrand, M., \& Gamoran, A. (2003). Discussion-based approaches to developing understanding: Classroom instruction and student performance in middle and high school English. American Educational Research Journal, 40(3), 685--730. 
Brandt, R. (2000). On teaching brains to think: A conversation with Robert Sylwester. Educational Leadership, 57(7), 72--75.

Gayle, B., Preiss, R., \& Allen, M. (2006). How effective are teacher-initiated classroom questions in enhancing student learning. Classroom Communication And Instructional Processes: Advances Through Meta-Analysis, 279--293.

Gayle, B. (2006). Classroom communication and instructional processes (1st ed.). Mahwah, N.J.: Lawrence Erlbaum Associates.

Haynes, F. (1990). Richard W. Paul, Critical Thinking: What Every Person Needs to Know to Survive in a Rapidly Changing World, Centre for Critical Thinking and Moral. Wiley Online Library.

Holme, T. (1992). Using the Socratic method in large lecture courses: Increasing student interest and involvement by forming instantaneous groups. Journal Of Chemical Education, 69(12), 974.

Inhelder, B., \& Piaget, J. (1958). The growth of logical thinking from childhood to adolescence (1st ed.). [New York]: Basic Books.

Overholser, J. (1992). Socrates in the classroom. The Social Studies, 83(2), 77--82.

Paul, R., \& Elder, L. (2000). The Miniature Guide to the Improvement of Instruction: 32 Practical Ideas [Handbook]. Dillon Beach, Calif.: Foundation for Critical Thinking.

Paul, R., \& Elder, L. (2001). Critical thinking (1st ed.). Upper Saddle River, N.J.: Prentice Hall.

Paul, R., \& Elder, L. (2006). The thinker's guide to the art of Socratic questioning (1st ed.). Dillon Beach, Calif.: Foundation for Critical Thinking.

Paul, R., Willsen, J., \& Binker, A. (1993). Critical thinking (1st ed.). Santa Rosa, CA: Foundation for Critical Thinking.

Paul, R. (2001). Training for Trainers: Teaching Critical Thinking Strategies to Colleagues. Lecture, Sonoma State University, Sonoma, California.

Piaget, J., \& Cook, M. (1977). The origin of intelligence in the child (1st ed.). Harmondsworth: Penguin.

Precel, K., Eshet-Alkalai, Y., \& Alberton, Y. (2009). Pedagogical and design aspects of a blended learning course. The International Review Of Research In Open And Distance Learning, 10(2).

Ros'e, C., Moore, J., VanLehn, K., \& Allbritton, D. (2001). A comparative evaluation of socratic versus didactic tutoring, 897--902.

Seifert, M. (1997). Socratic Teaching. Retrieved 17 April 2011, from http://lonestar.texas.net/ mseifert/crit3.html

Sigel, I., Brodzinsky, D., \& Golinkoff, R. (1981). New directions in Piagetian theory and practice (1st ed.). Hillsdale, N.J.: L. Erlbaum Associates.

Wenning, C., Holbrook, T., \& Stankevitz, J. (2006). ). Engaging students in conducting Socratic dialogues: Suggestions for science teachers. Journal Of Physics Teacher Education Online, 4(1), 10-13.

Yang, Y., Newby, T., \& Bill, R. (2005). Using Socratic questioning to promote critical thinking skills through asynchronous discussion forums in distance learning environments. The American Journal Of Distance Education, $19(3), 163--181$. 